\title{
Human rhinovirus infection in young African children with acute wheezing
}

Heidi E Smuts ${ }^{1 *}$, Lesley J Workman², Heather J Zar $^{3}$

\begin{abstract}
Background: Infections caused by human rhinoviruses (HRVs) are important triggers of wheezing in young children. Wheezy illness has increasingly been recognised as an important cause of morbidity in African children, but there is little information on the contribution of HRV to this. The aim of this study was to determine the role of HRV as a cause of acute wheezing in South African children.

Methods: Two hundred and twenty children presenting consecutively at a tertiary children's hospital with a wheezing illness from May 2004 to November 2005 were prospectively enrolled. A nasal swab was taken and reverse transcription PCR used to screen the samples for HRV. The presence of human metapneumovirus, human bocavirus and human coronavirus-NL63 was assessed in all samples using PCR-based assays. A general shell vial culture using a pool of monoclonal antibodies was used to detect other common respiratory viruses on $26 \%$ of samples. Phylogenetic analysis to determine circulating HRV species was performed on a portion of HRV-positive samples. Categorical characteristics were analysed using Fisher's Exact test.

Results: HRV was detected in 128 (58.2\%) of children, most (72\%) of whom were under 2 years of age. Presenting symptoms between the HRV-positive and negative groups were similar. Most illness was managed with ambulatory therapy, but 45 (35\%) were hospitalized for treatment and 3 (2\%) were admitted to intensive care. There were no in-hospital deaths. All 3 species of HRV were detected with HRV-C being the most common (52\%) followed by HRV-A (37\%) and HRV-B (11\%). Infection with other respiratory viruses occurred in 20/128 (16\%) of HRV-positive children and in 26/92 (28\%) of HRV-negative samples.
\end{abstract}

Conclusion: HRV may be the commonest viral infection in young South African children with acute wheezing. Infection is associated with mild or moderate clinical disease.

\section{Background}

Wheezing is a frequent manifestation of lower respiratory tract infection (LRTI) in infants and young children. Viral infections are the commonest cause of acute wheezing. Several respiratory viruses, including respiratory syncytial virus (RSV), influenza viruses, parainfluenza viruses, enteroviruses, human coronaviruses, human metapneumovirus and human bocavirus have been associated with wheezy illness [1-5].

With the improvement of molecular techniques the frequency of HRV detection in clinical samples has increased dramatically [6-8] providing increasing evidence that HRV infection may be associated with LRTI

\footnotetext{
* Correspondence: Heidi.Smuts@uct.ac.za

'Division Medical Virology/NHLS, Department of Clinical Laboratory Sciences, University of Cape Town, Cape Town, South Africa

Full list of author information is available at the end of the article
}

including bronchiolitis, pneumonia, asthma exacerbations or influenza-like illnesses [9]. A recent populationbased study showed that HRV was detected in $26 \%$ of children under 5 years of age hospitalized with respiratory symptoms or fever [10]. Subsequently, studies in high income countries have confirmed the importance of HRV as a cause of severe LRTI in young children requiring hospitalization $[11,12]$. It is unclear if the diverse spectrum of clinical illnesses associated with HRV infection is related to host factors, the infecting HRV type or both. Recent evidence suggests that infection with HRV-C may result in more severe disease [12-16].

Since the first isolation of HRV in 1953 [17] approximately 100 serotypes have been described and new types are being discovered indicating that this genus is considerably more varied than previously recognized. Based on sequence analysis, antiviral susceptibilities and receptor

\section{Biomed Central}


usage HRV was until recently divided into 2 groups; HRV-A and HRV-B [18]. However, a third and possible fourth grouping, HRV-C and HRV-D, have been identified after sequence analysis of HRV types identified some which did not cluster with HRV-A, HRV-B or other species within the genus Enterovirus [15,16,19-23]. HRV-C has a global distribution, with a prevalence intermediate with HRV-A and HRV-B [24].

The importance of HRV as a cause of acute wheezing illness in infants and young children has not been studied in African children. The aim of this study was to investigate the prevalence of HRV in African children with acute wheezing.

\section{Methods}

\section{Study design}

A prospective study of children aged 2 months to 5 years presenting with acute wheezing to Red Cross War Memorial Children's Hospital (RCCH) from May 2004 to November 2005 (2 winter seasons) was undertaken. $\mathrm{RCCH}$ is a public paediatric tertiary hospital in Cape Town, South Africa that provides care to children mostly from poor socio-economic backgrounds. Children were eligible if they had a history of cough or difficulty breathing within the prior 5 days and expiratory wheezing on auscultation or hyperinflation of the chest. Exclusion criteria were known underlying cardiac or chronic pulmonary disease (other than asthma), presence of stridor or daily treatment with oral corticosteroids for more than 2 days prior. Eligible children were sequentially enrolled from Monday to Friday during working hours. Clinical and sociodemographic information were recorded. Written, informed consent was obtained from a parent or guardian. The study was approved by the Human Research Ethics Committee of the Faculty of Health Sciences, University of Cape Town, South Africa.

\section{Nasal samples}

A nasal swab was obtained using a dry sterile cotton swab inserted sequentially into each nostril to a depth of 2-3 cm and slowly withdrawn in a rotating motion as recommended by the WHO guidelines on the collection of human specimens [25]. The tip of the swab was placed in viral transport medium and transported to the Virology laboratory on the same day. After a clarification step (2000 rpm for 7 minutes) the medium was stored at $-20^{\circ} \mathrm{C}$.

\section{Rhinovirus detection}

RNA was extracted from $200 \mu$ of the respiratory sample using the Talent Seek Viral RNA kit (Talent Sri, Trieste, Italy) according to the manufacturer's instructions. The purified RNA sample was converted into cDNA using random primers (Roche Diagnostics $\mathrm{GmbH}$, Mannheim,
Germany) and the iScript cDNA synthesis kit (Bio-Rad, CA, USA). Samples were screened for HRV using PCR primers targeting the 5' untranslated region (5'UTR) which had previously been shown to amplify all known serotypes and HRV-C species [22]. In the first reaction $10 \mu \mathrm{l}$ cDNA was added to a $50 \mu \mathrm{l}$ PCR mix containing 2 IU Supertherm polymerase (JMR Holdings, Kent, UK), $15 \mathrm{mM}$ Tris- $\mathrm{HCl}$ (pH 8), $50 \mathrm{mM} \mathrm{KCl}, 1.5 \mathrm{mM} \mathrm{MgCl}$, $200 \mu \mathrm{mol} / \mathrm{L}$ each dNTP (Roche Diagnostics GmbH, Mannheim, Germany) and $0.2 \mu \mathrm{mol} / \mathrm{L} \mathrm{P} 1-1$ and P3-1 primers [22]. Amplification was performed on a Thermo Hybaid PxE 0.2 thermal cycler (Thermo Scientific, Waltham, MA, USA), with the following conditions: 1 cycle of $94^{\circ} \mathrm{C}$ for 2 minutes, 40 cycles of $94{ }^{\circ} \mathrm{C}$ for $15 \mathrm{~s}, 50^{\circ} \mathrm{C}$ for $25 \mathrm{~s}$, and $72^{\circ} \mathrm{C}$ for $35 \mathrm{~s}$, and a final elongation step at $72^{\circ} \mathrm{C}$ for 7 minutes. The second round semi-nested PCR was performed on $2.5 \mu \mathrm{L}$ outer PCR product using the same basic master mix ingredients containing $0.2 \mu \mathrm{mol} / \mathrm{L}$ P1-1, P2-1, P2-2, and P2-3 primers [22]. Cycling conditions were as for the first round PCR with an increase in annealing temperature to $55^{\circ} \mathrm{C}$. Amplified products were separated by electrophoresis in $2 \%$ agarose gel, and visualized under UV irradiation after staining with ethidium bromide. The expected sizes of the outer and inner HRV PCR products were $390 \mathrm{bp}$ and $300 \mathrm{bp}$ respectively. VP4/ VP2 amplification was performed as above on a selection of HRV-C and HRV-A samples to differentiate HRV-Ca and $\mathrm{HRV}-\mathrm{Cc}$ variants using the primers described by Huang et al. [19]. All work was performed in an ISO15189 accredited molecular laboratory which employs strict precautions to prevent contamination.

\section{Detection of other respiratory viruses}

A general shell vial culture using a pool of monoclonal antibodies detecting respiratory syncytial virus (RSV), influenza A and B viruses, adenovirus and parainfluenza viruses 1, 2 and 3 was performed on every $4^{\text {th }}$ sample ( $\mathrm{n}=$ 58 ) by an indirect immunofluorescence assay (Light Diagnostics, Chemicon International, CA, USA). Further specific virus identification on pool-positive samples was not undertaken. All samples were screened for human metapneumovirus (hMPV), human coronavirus-NL63 (HCoVNL63) and human bocavirus (HBoV) by RT-PCR and PCR as previously described [26].

\section{Sequencing and Phylogenetic analysis}

The HRV 5'UTR and VP4/VP2 PCR products were purified with a QIAquick PCR purification kit (Qiagen, Hilden, Germany) and sequenced on an ABI 310 sequencer with a fluorescent dye terminator kit (Applied Biosystems, Foster City, CA, USA). The nucleotide sequences were aligned with known HRV sequences from GenBank, including HRV Ca and Cc reference strains [27], using CLUSTALX software. A neighbour-joining phylogenetic tree was 
constructed using the Treecon software program (version $1.3 \mathrm{~b}$ ) with 500 bootstrap resamplings [28]. GenBank accession numbers are HM623207-HM623277.

\section{Statistical analysis}

Continuous variables were expressed as median and inter quartile ranges and compared using Kruskal-Wallis Test. Categorical characteristics were analysed using Fisher's Exact test. A p-value of $<0.05$ was considered statistically significant.

\section{Results}

Two hundred and twenty children, median $\left(25^{\text {th }}-75^{\text {th }}\right.$ percentile) age 12.2 (6.2-27.5) months, were enrolled and had a nasal swab taken. More than half, 114 (51.8\%), were under 12 months, while 163 (74.1\%) were less than 24 months of age, Table 1 . HRV was detected in 128 (58.2\%) of the samples. Most HRV-positive children were under 24 months of age $(92 / 128 ; 71.8 \%)$ while half were under 12 months. There was no difference in the previous number of wheezing episodes in HRV-positive compared to negative children. The clinical symptoms and HRV status of children admitted to hospital and those treated as an out-patient is presented in Table 2. Wheezing was more common in hospitalized children (93\%) and the total duration of symptoms was shorter.

HRV was detected throughout the year although there was a peak in spring (September-November of 2004 and 2005) and another in February-April 2005 (autumn) (Figure 1).

Co-infection with hMPV, HBoV and HCoV-NL63 was found in 8 (6.3\%), $6(4.7 \%)$ and $1(0.8 \%)$ of the 128 HRV-positive samples respectively. Of the $92 \mathrm{HRV}$ negative samples $5(5.4 \%)$ were hMPV positive, 10 (10.9\%) HBoV positive and 3 (3.3\%) $\mathrm{HCoV}$ positive. Of the 58 samples screened for the common respiratory viruses by general shell vial culture $14(24.1 \%)$ were positive; 4 (6.9\%) HRV-positive and 10 (17.2\%) HRVnegative.

Sequencing of the 5' UTR was performed on 71/128 (55.5\%) positive samples using convenience sampling ensuring each month of the study period was included, but without prior knowledge of patient data. Figure 2 shows the phylogenetic distribution. HRV-C can be divided into 2 variants, $\mathrm{Ca}$ or $\mathrm{Cc}$, with either HRV-Alike or HRV-C-like 5'UTR's respectively. HRV-Ca sequences $(n=24)$ were interspersed within the HRV-A region of the phylogenetic tree. The remaining HRV-C samples $(n=13)$ formed a separate branch with the

Table 1 Clinical and demographic details of HRV-positive and negative children

\begin{tabular}{|c|c|c|c|c|}
\hline & $\begin{array}{l}\text { HRV-positive } \\
\mathrm{n}=128(58.2 \%)\end{array}$ & $\begin{array}{l}\text { HRV-negative } \\
\mathrm{n}=92(41.8 \%)\end{array}$ & OR $(95 \% \mathrm{Cl})$ & $\rho$-value \\
\hline Age (months) (median \& IQR) & $13.3(6.0-28.2)$ & $11.7(6.7-24.6)$ & $1.00(0.99-1.02)$ & 0.68 \\
\hline Male n (\%) & $76(59)$ & $52(41)$ & $0.89(0.52-1.53)$ & 0.67 \\
\hline \multicolumn{5}{|l|}{ Clinical symptoms n (\%) } \\
\hline Cough & $114(89)$ & $83(90)$ & $1.13(0.47-2.74)$ & 0.78 \\
\hline Wheeze & $108(84)$ & $79(86)$ & $1.13(0.53-2.40)$ & 0.76 \\
\hline Breathing difficulty & $68(53)$ & $43(47)$ & $0.77(0.45-1.32)$ & 0.35 \\
\hline Rhinorrhea & $86(67)$ & $59(64)$ & $0.87(0.50-1.53)$ & 0.64 \\
\hline Night waking & $75(59)$ & $52(57)$ & $0.92(0.53-1.58)$ & 0.76 \\
\hline Fever $>37.5 \mathrm{C}$ & $43(34)$ & $46(50)$ & $1.98(1.14-3.42)$ & 0.02 \\
\hline Diarrhoea & $17(13)$ & $10(11)$ & $0.80(0.35-1.83)$ & 0.60 \\
\hline Vomiting & $51(40)$ & $23(25)$ & $0.50(0.28-0.91)$ & 0.02 \\
\hline Duration of symptoms (days) (median \& IQR) & $3(2-7)$ & $4(2-7)$ & $0.99(0.96-1.02)$ & 0.58 \\
\hline Previous episodes of wheezing (median \& IQR) & $3(2-6)$ & $3(2-10)$ & $0.98(0.94-1.02)$ & 0.27 \\
\hline $\mathrm{n}=0(\%)$ & $29(22.7)$ & $21(23)$ & & \\
\hline $\mathrm{n}=<3(\%)$ & $40(31.2)$ & $22(24)$ & $0.98(0.35-2.79)$ & 0.97 \\
\hline $\mathrm{n}=\geq 3(\%)$ & $59(46.1)$ & $49(53)$ & $0.99(0.94-1.03$ & 0.57 \\
\hline \multicolumn{5}{|l|}{ Hospital admission n (\%) } \\
\hline General ward & $45(35.2)$ & $26(28.3)$ & $1.38(0.77-2.46)$ & 0.28 \\
\hline ICU & $3(2.3)$ & $4(4.4)$ & $1.90(0.41-8.67)$ & 0.41 \\
\hline \multicolumn{5}{|l|}{ Risk factors n (\%) } \\
\hline Premature birth (< 38 weeks gestation) & $16(13)$ & 19(21) & $0.55(0.37-1.14)$ & 0.10 \\
\hline Smoker in house & $54(45)$ & $4(50)$ & $1.37(0.80-2.35)$ & 0.25 \\
\hline Relative with asthma & $45(35)$ & $2(28)$ & $1.38(0.34-1.11)$ & 0.11 \\
\hline
\end{tabular}

$\mathrm{HRV}=$ human rhinovirus; $\mathrm{IQR}=$ interquartile range; $\mathrm{OR}=$ odds ratio; $95 \% \mathrm{Cl}=95 \%$ confidence interval; $\rho$-value = probability value. 
Table 2 Clinical profile of children admitted to hospital compared to those treated as an out-patient

\begin{tabular}{|c|c|c|c|c|}
\hline & Hospitalized & Out-patient & OR $(95 \% \mathrm{Cl})$ & $\rho$-value \\
\hline & $\mathrm{n}=71(32.3 \%)$ & $n=149(67.7 \%)$ & & \\
\hline \multicolumn{5}{|l|}{ Clinical symptoms $n(\%)$} \\
\hline Cough & $60(85)$ & 137(91) & $2.09(0.87-5-01)$ & 0.10 \\
\hline Wheeze & $66(93)$ & $121(81)$ & $0.33(0.12-0.89)$ & 0.03 \\
\hline Breathing difficulty & $35(49)$ & $76(51)$ & 1.07(0.61-1.88) & 1.07 \\
\hline Rhinorrhea & $43(61)$ & 102(69) & $1.41(0.78-2.54)$ & 0.25 \\
\hline Night waking & $38(54)$ & $89(60)$ & $1.29(0.73-2.27)$ & 0.38 \\
\hline Fever $>37.5 \mathrm{C}$ & $30(42)$ & $59(40)$ & $0.89(0.51-1.59)$ & 0.71 \\
\hline Diarrhoea & $11(16)$ & $16(11)$ & $0.66(0.29-1.50)$ & 0.32 \\
\hline Vomiting & 24(34) & $50(34)$ & $0.99(0.54-1.80)$ & 0.97 \\
\hline Duration of symptoms (days) (median \& IQR) & $3(1-4)$ & $4(2-7)$ & $0.94(0.90-0.99)$ & 0.02 \\
\hline HRV positive status n (\%) & $45(63)$ & $83(56)$ & $1.38(0.77-2.46)$ & 0.28 \\
\hline
\end{tabular}

$\mathrm{HRV}=$ human rhinovirus; $\mathrm{IQR}=$ interquartile range; $\mathrm{OR}=$ odds ratio; $95 \% \mathrm{Cl}=95 \%$ confidence interval; $\rho$-value $=$ probability value.

HRV-C-like 5'UTR. HRV-C was the most prevalent (37/ $71 ; 52.1 \%)$ followed by HRV-A $(26 / 71 ; 36.6 \%)$ and HRVB $(8 / 71 ; 11.3 \%)$. HRV-C was found throughout the year while HRV-A had peaks in the spring and autumn seasons and HRV-B was sporadically detected (Figure 3).

Presenting symptoms or signs in HRV-infected and uninfected children were similar, except for fever which was less common in HRV-infected group of children and vomiting which was more common (Table 1). Most children with HRV infection had mild illness, although $45(35.2 \%)$ required hospitalisation and $3(2.3 \%)$ were admitted to the intensive care unit. The median (IQR) duration of hospitalisation was 1 (1-4) days; there was no difference in the duration of hospitalisation between HRV-infected and uninfected children. There were no in-hospital deaths. Of those admitted to hospital and where a HRV sequencing result was available $(\mathrm{n}=15) 8$ (25.8\%) were typed as species C, 5 species A (16.1\%) and 2 species $B(6.4 \%)$.

\section{Discussion}

HRV was the commonest viral infection in young African children presenting to a tertiary children's hospital in South Africa with acute wheezing. HRV has previously been reported in older children with wheezing or asthma exacerbations [5,29]. However, there is now accumulating evidence that HRV-associated illness occurs in young children with LRTI with many studies from other areas of the world reporting HRV detection rates from $24 \%$ to $48 \%[11,30,31]$, and as high as $78 \%$ in predisposed

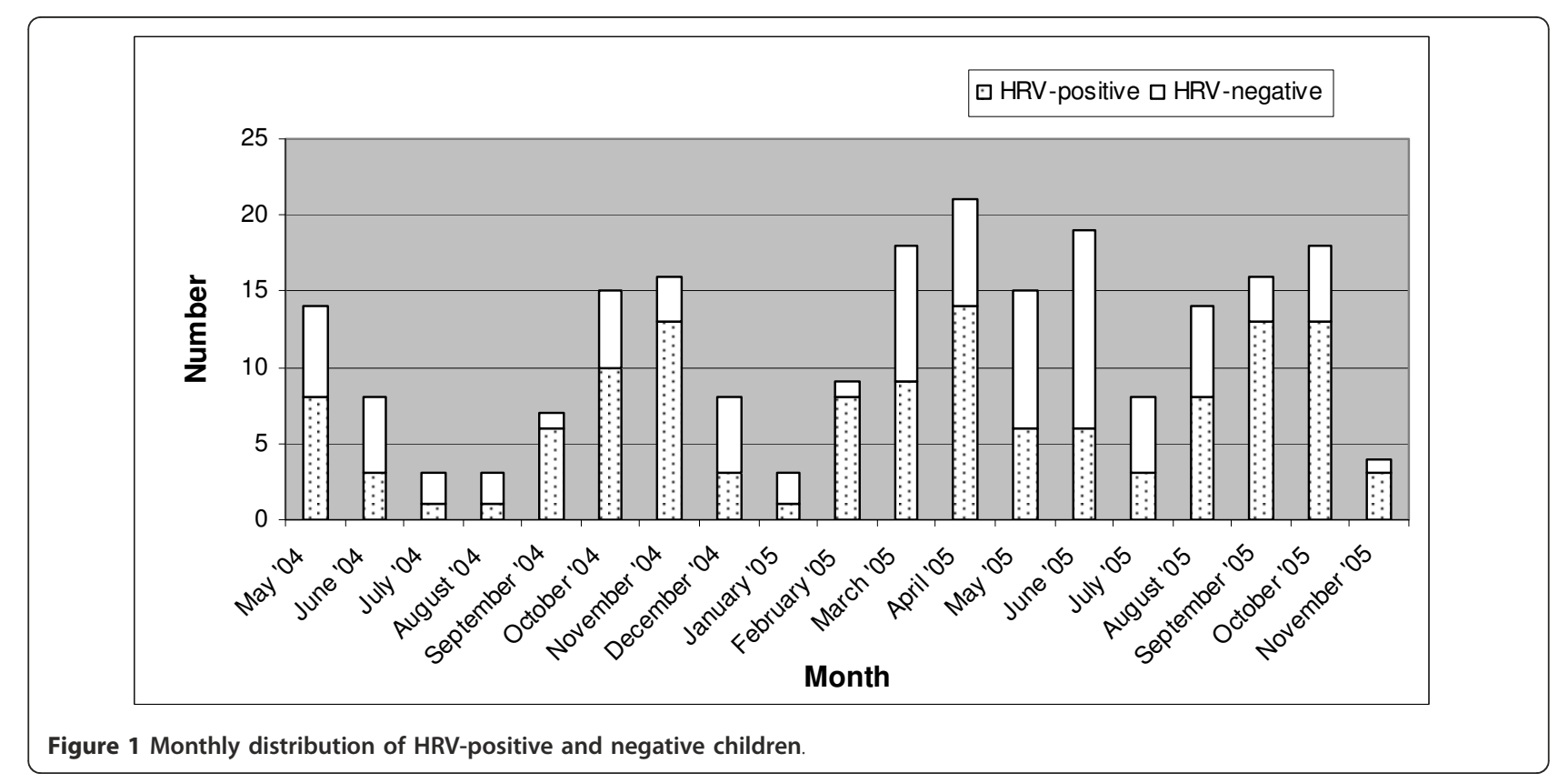




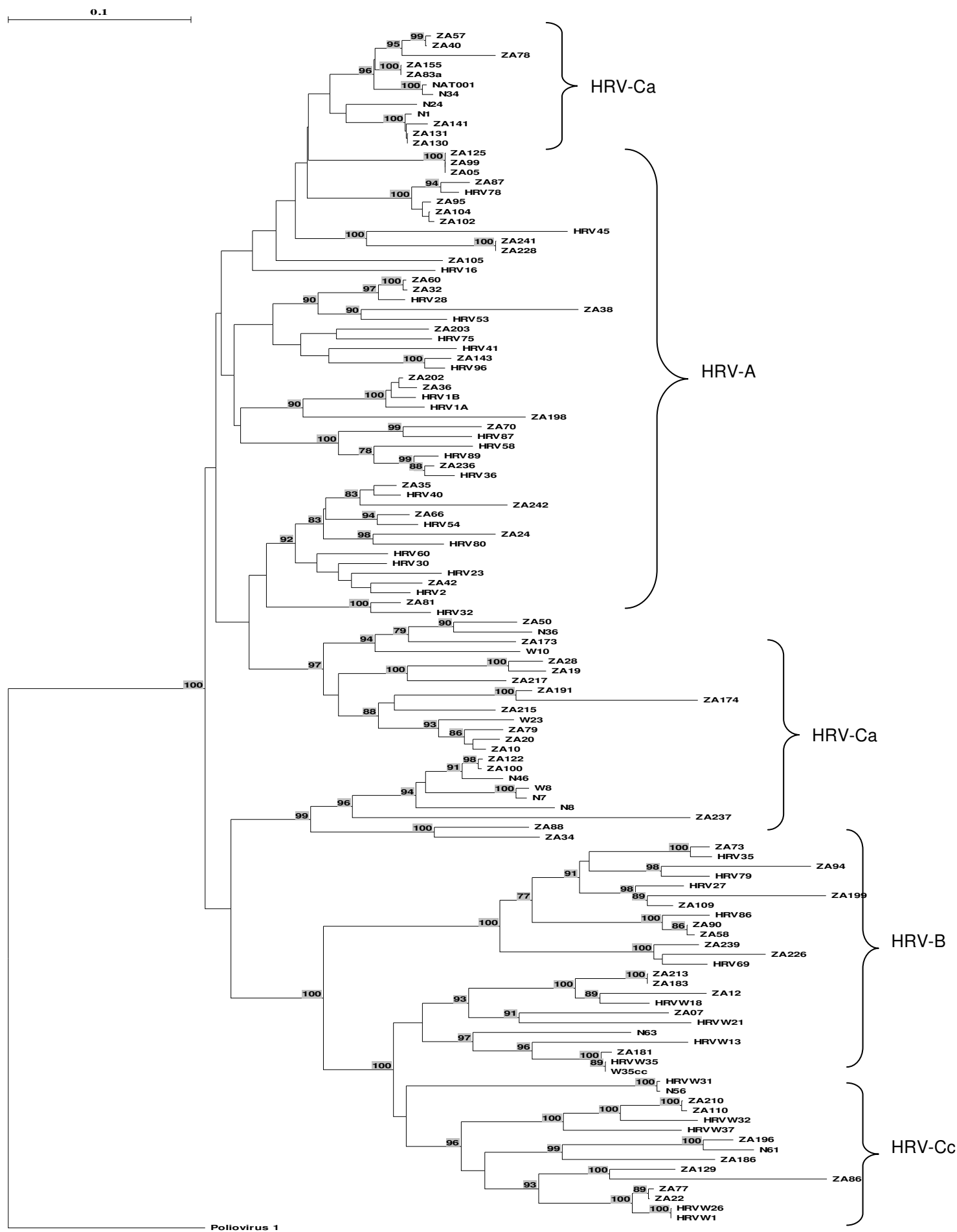

Figure 2 Phylogenetic tree of the $5^{\prime}$ UTR depicting the relationship between study samples and HRV-A, HRV-B and novel HRV-Ca and Cc species obtained from the GenBank database.

children [32]. Consistent with these, $72 \%$ of the HRVpositive children were under 2 years. This data is also consistent with prior studies that report mild to moderate illness in most children [11], although in this study a third required hospitalization. The study suggests that HRV is responsible for a large burden of illness in young African children with associated implications for health care utilisation. 


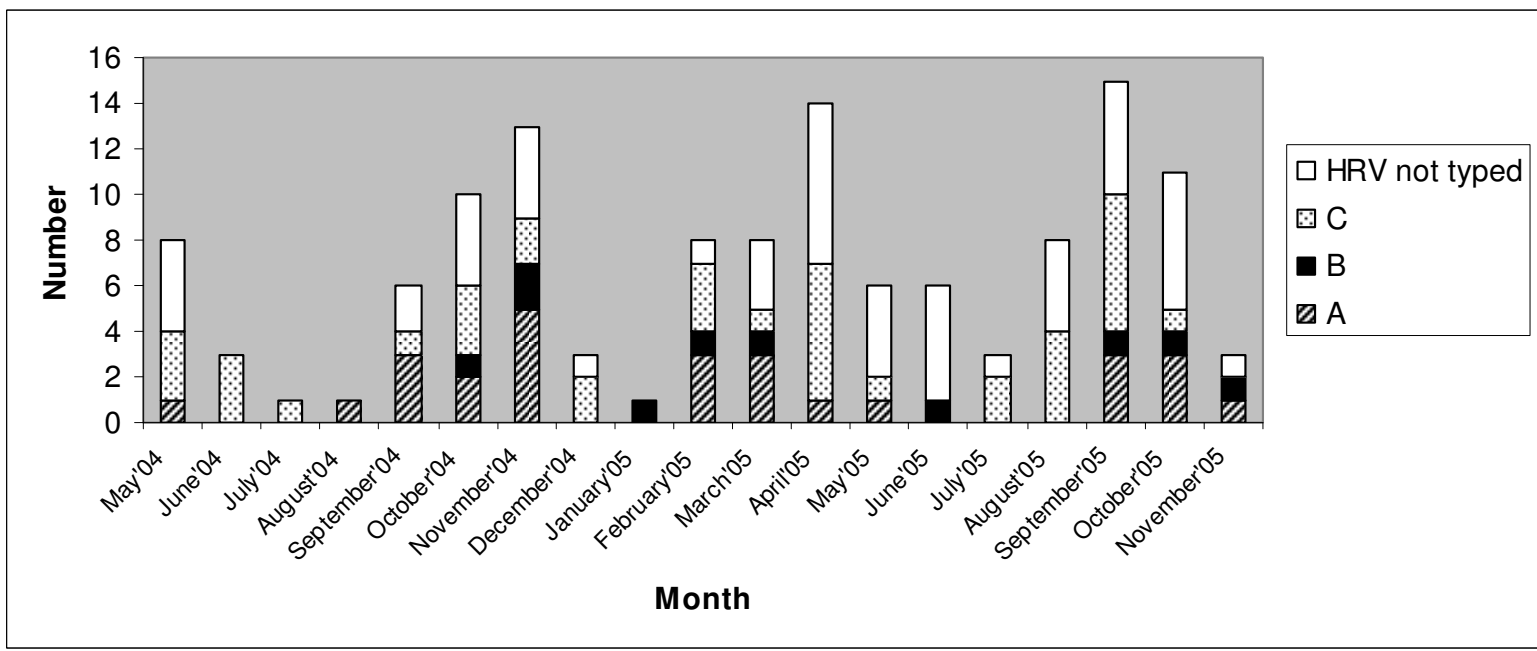

Figure 3 Monthly distribution of the different HRV species

HRV has also been associated with recurrent wheezing and with the development of asthma in older children [32-35]. HRV-induced wheezing during the first 3 years of life was associated with a 10 fold risk of developing asthma by six years in a USA cohort of infants at high risk for developing asthma [32]. Asthma is the most common chronic childhood illness in South African children affecting 10-20\% of adolescents; the prevalence has increased over the last decade [36]. The role of HRV in the inception and development of asthma and in triggering acute asthma episodes in African children needs further study.

Consistent with other studies, HRV was identified throughout the year with peaks of activity in the spring of 2004 and 2005 and autumn of 2005 [3,10,35]. Interestingly this pattern was more prominent with HRV-A than HRV-C and HRV-B which were detected throughout the year or sporadically. Seasonal variation is a common feature of many respiratory viruses, including RSV, influenza, parainfluenza virus, and although the causes of this variation are largely unknown, one possible explanation may be as a result of viral interference where one respiratory virus predominates and prevents other viruses from establishing infection at the same time. As the study was of 18 months duration any inferences about seasonality are difficult to make. However, the study period included 2 winter seasons. Further long term studies of the epidemiology of viral infections and HRV specifically in African children are needed.

Phylogenetic analysis of the 5'UTR of HRV-positive samples showed the circulation of all 3 species in Cape Town, South Africa. In this study, and as reported by Huang et al. [19], HRV-C was the most prevalent followed by HRV-A and HRV-B. This distribution pattern is different from other studies where HRV-A was more frequently detected; this may vary depending on the population $[21,24,37]$. Consistent with previous studies HRV-C was the common type in children with wheezing and asthma $[13,21,37]$. Typing using the 5'UTR may underestimate the true number of $\mathrm{HRV}-\mathrm{C}$ samples as there is evidence that recombination with HRV-A species at this site is a common occurrence, resulting in these types grouping with HRV-A species instead of HRV-C $[19,38]$. However, limited sequencing of the VP4/VP2 region (data not shown) and inclusion of sequences of HRV-C with HRV-A-like 5'UTR's in the phylogenetic analysis confirmed that HRV-C was the most common species in this population, with HRV-Ca more prevalent (65\%) than HRV-Cc. Further confirmation is that all HRV-Ca sequences from this study grouped phylogenetically with GenBank-derived HRV isolates that have been confirmed to be true HRV-C types based on the classification proposed by Simmonds et al [27]. As most children presented with mild or moderate illness, and as only a subgroup of HRV isolates were sub-typed, we were unable to investigate the association between HRV species and clinical severity; this requires further investigation.

The study has some limitations. A control group of asymptomatic or clinically well children from the same time period were not included. However, previous studies have reported that HRV is more frequently found in sick children than in asymptomatic children $[4,11]$. HRV can be shed from the nasophaynx for 10 to 14 days in immunocompetent individuals with extended shedding in immunocompromised patients [9]. The immune status of children enrolled in this study was not recorded, although it can be inferred that some 
children may have been HIV-positive as South Africa is a high HIV burden country. Thus detection of HRV in some children with wheezy illness may therefore be an incidental finding due to extended shedding. Due to resource limitations, only a subset of specimens could be tested for the common respiratory viruses (RSV, influenza virus $A$ and $B$, parainfluenza viruses $1,2,3$ and adenovirus) using the relatively insensitive general shell vial culture assay which does not provide sufficient information to determine the role of co-infection and disease severity. Finally, the study did not test for all known respiratory viruses (e.g. human coronavirus $229 \mathrm{E}$ and OC43, and human parainfluenza type 4) and recently discovered viruses (e.g. human coronavirus HKU1 and polyomaviruses $\mathrm{K} 1$ and $\mathrm{Wu}$ ) which may also play a role in wheezy illness.

\section{Conclusions}

HRV may be the commonest virus in young African children with acute wheezing. Infection is associated with mild or moderate clinical disease. Longitudinal studies with frequent samplings and HRV type identification are needed to investigate the role of HRV in wheezing illness in African children and their long term outcome.

\section{Acknowledgements \\ We thank the research nurses Ms. M. Roux and Ms. A. Joachim and Dr S Streun for enrolment of children and the Virology laboratory staff at C18 Groote Schuur Hospital for performing the indirect immunofluorescence shell vial assays. We are grateful for the support of the staff in the ambulatory section of Red Cross Children's Hospital.}

\section{Author details}

'Division Medical Virology/NHLS, Department of Clinical Laboratory Sciences, University of Cape Town, Cape Town, South Africa. ${ }^{2}$ Division of Clinical Pharmacology, Department of Medicine, University of Cape Town, Cape Town, South Africa. ${ }^{3}$ Department of Paediatrics and Child Health, University of Cape Town, Red Cross War Memorial Children's Hospital, Cape Town, South Africa.

\section{Authors' contributions}

HS conceived the study, carried out experimental studies, analyzed the sequence data and drafted manuscript. LW performed data management and statistical analyses. $\mathrm{HZ}$ conceived the study, obtained funding, supervised the clinical study and participated in manuscript preparation. All authors read and approved the final manuscript.

\section{Competing interests}

The authors declare that they have no competing interests.

Received: 17 November 2010 Accepted: 15 March 2011 Published: 15 March 2011

\section{References}

1. Allander T, Jartti T, Gupta S, Niesters HG, Lehtinen P, Osterback R, Vuorinen T, Waris M, Bjerkner A, Tiveljung-Lindell A, van den Hoogen BG, Hyypiä T, Ruuskanen O: Human bocavirus and acute wheezing in children. Clin Infect Dis 2007, 44:904-910.

2. Chung J-Y, Han TH, KIM SW, Kim CK, Hwang E-S: Detection of viruses identified recently in children with acute wheezing. J Med Virol 2007, 79:1238-1243.
3. Jartti $T$, Lehtinen $P$, Vuorinen $T$, Osterback $R$, van den Hoogen $B$, Osterhaus $A D$, Ruuskanen $O$ : Respiratory picornaviruses and respiratory syncytial virus as causative agents of acute expiratory wheezing in children. Emerg Infect Dis 2004, 10:1095-1101.

4. Wilson NM: Virus infections, wheeze and asthma. Paed Resp Reviews 2003, 4:184-192.

5. Johnston SL, Pattemore PK, Sanderson G, Smith S, Lampe F, Josephs L, Symington P, O'Toole S, Myint SH, Tyrrell DA, Holgate ST: Community study of the role of viral infections in exacerbations of asthma in 9-11 year old children. BMJ 1995, 310:1225-1229.

6. Lu X, Holloway B, Dare RK, Kuypers J, Yagi S, Williams JV, Hall CB, Erdman DD: Real-time reverse transcription -PCR assay for comprehensive detection of human rhinoviruses. J Clin Microbiol 2008, 46:533-539.

7. Wright PF, Deatly AM, Karron RA, Belshe RB, Shi JR, Gruber WC, Zhu Y, Randolph VB: Comparison of results of detection of rhinovirus by PCR and viral culture in human nasal wash specimens from subjects with and without clinical symptoms of respiratory illness. J Clin Microbiol 2007, 45:2126-2129.

8. Loens K, Goossens H, de Laat C, Foolen H, Oudshoorn P, Pattyn S, Sillekens $P$, leven M: Detection of rhinoviruses by tissue culture and two independent amplification techiniques, nucleic acid sequence-based amplification and reverse transcription-PCR, in children with acute respiratory infections during a winter season. J Clin Microbiol 2006, 44:166-171.

9. Mackay IM: Human rhinoviruses: the cold wars resume. J Clin Virol 2008, 42:297-320.

10. Miller EK, Lu X, Erdman DD, Poehling KA, Zhu Y, Griffin MR, Hartert TV, Anderson $L$, Weinberg GA, Hall CB, Iwane MK, Edwards KM, New Vaccine Surveillance Network: Rhinovirus-associated hospitalizations in young children. J Infect Dis 2007, 195:773-781.

11. Piotrowska Z, Vazquez M, Shapiro ED, Weibel C, Ferguson D, Landry ML, Kahn JS: Rhinoviruses are a major cause of wheezing and hospitalization in children less than 2 years of age. Pediatr Infect Dis J 2009, 28:25-29.

12. Peltola V, Jartti T, Putto-Laurila A, Susi P, Hyypia T, Ruuskanan O: Rhinovirus infection in children: a retrospective and prospective hospital-based study. J Med Virol 2009, 81:1831-1838.

13. Miller EK, Edwards KM, Weinberg GA, Iwane MK, Griffin MR, Hall CB, Zhu Y, Szilagyi PG, Morin L-L, Heil LH, Lu X, Williams JV: A novel group of rhinoviruses is associated with asthma hospitalizations. Allergy Clin Immunol 2009, 123:98-104.

14. Piralla A, Rovida F, Campanini G, Rognoni V, Marchi A, Locatelli F, Gerna G: Clinical severity and molecular typing of human rhinovirus $C$ strains during a fall outbreak affecting hospitalized patients. J Clin Virol 2009, 45:311-317.

15. McErlean P, Shackelton LA, Lambert SB, Nissen MD, Sloots TP, Mackay IM: Characterization of a newly identified human rhinovirus, HRV-QPM, discovered in infants with bronchiolitis. J Clin Virol 2007, 39:67-75.

16. Renwick N, Schweiger B, Kapoor V, Liu Z, Villari J, Bullmann R, Meithing R, Briese T, Lipkin Wl: A recently identified rhinovirus genotype is associated with severe respiratory-tract infection in children in Germany. J Infect Dis 2007, 196:1745-1760.

17. Andrewes $\mathrm{CH}$, Chaproniere DM, Gompels AEH, Pereira HG, Roden AT: Propagation of common-cold virus in tissue cultures. Lancet 1953, 265:546-547.

18. Patel NR, Demenczuk TM, Watanyar A, Herbertz T, Collett MS, Pevear DC: VP1 sequencing of all human rhinovirus serotypes: insights into genus phylogeny and susceptibility to antiviral capsid-binding compounds. J Virol 2004, 78:3663-3674

19. Huang T, Wang W, Bessaud M, Ren P, Sheng J, Yan H, Zhang J, Lin X, Wang $Y$, Delpeyroux F, Deubel V: Evidence of recombination and genetic diversity in human rhinoviruses in children with acute respiratory infection. PLoS One 2009, 4:e6355.

20. Palmenberg AC, Spiro D, Kuzmickas R, Wang S, Djikeng A, Rathe JA, FraserLiggett CM, Liggett SB: Sequencing and analyses of all known human rhinovirus genomes reveal structure and evolution. Science 2009, 324:55-59.

21. Lau SK, Yip CC, Tsoi HW, Lee RA, So LY, Lau YL, Chan KH, Woo PC, Yuen KY: Clinical features and complete genome characterization of a distinct human rhinovirus (HRV) genetic cluster, probably representing a previously undetected HRV species, HRV-C, associated with acute respiratory illness in children. J Clin Microbiol 2007, 45:3655-3664. 
22. Lee WM, Kiesner C, Pappas T, Lee I, Grindle K, Jartti T, Jakiela B, Lemanske RF, Shult PA, Gern JE: A diverse group of previously unrecognized human rhinoviruses are common causes of respiratory illness in infants. PLoS One 2007, 2:e966.

23. Arden $K E$, Faux $C E$, O'Neill NT, McErlean P, Nitsche A, Lambert $S B$, Nissen MD, Sloots TP, Mackay IM: Molecular characterization and distinguishing features of a novel rhinovirus (HRV) C, HRVC-QCE, detected in children with fever, cough and wheeze during 2003. I Clin Virol 2010, 47:219-223.

24. Briese T, Renwick N, Venter M, Jarman RG, Ghosh D, Kondgen S, Shrestha SK, Hoegh AM, Casas I, Adjogoua EV, Akoua-Koffi C, Myint KS, Williams DT, Chidlow G, van den Berg R, Calvo C, Koch O, Palacios G, Kapoor V, Villari J, Dominguez SR, Holmes KV, Harnett G, Smith D, Mackenzie JS, Ellerbrok H, Schweiger B, Schønning K, Chadha MS, Leendertz $F H$, et al: Global distribution of novel rhinovirus genotype. Emerg Infect Dis 2008, 14:944-947.

25. WHO guidelines for the collection of human specimens for laboratory diagnosis of avain influenza infection. [http:/www.who.int/csr/disease/ avian_influenza/guidelines/humanspecimens/en/], (accessed 10 January 2011).

26. Smuts H, Workman L, Zar HJ: Role of human metapneumovirus, human coronavirus NL63 and human bocavirus in infants and young children with acute wheezing. J Med Virology 2008, 80:906-912.

27. Simmonds P, Mclntyre C, Savolainen-Kopra C, Tapparel C, Mackay IM, Hovi T: Proposals for the classification of human rhinovirus species $C$ in genotypically assigned types. J Gen Virol 2010, 91:2409-2419.

28. Van de Peer Y, De Wachter R: TREECON for Windows: a software package for the construction and drawing of evolutionary trees for the Microsoft Windows environment. Comput Applic Biosci 1994, 10:569-570.

29. Kling S, Donninger H, Williams Z, Vermeulen J, Weinberg E, Latiff K, Ghildyal R, Bardin P: Persistence of rhinovirus RNA after asthma exacerbation in children. Clin Exp Allergy 2005, 35:672-678.

30. Kusel MMH, de Klerk NH, Holt PG, Kebadze T, Johnston SL, Sly PD: Role of respiratory viruses in acute upper and lower respiratory tract illness in the first year of life: a birth cohort study. Pediatr Infect Dis J 2006, 25:680-686.

31. Blomqvist S, Roivainen M, Puhakka T, Hovi T: Virological and serological analysis of rhinovirus infections during the first two years of life in a cohort of children. J Med Virol 2006, 66:263-268.

32. Hyvarinen MK, Kotaniemi-Syranen A, Reijonen TM, Korhonen K, Korppi MO Teenage asthma after severe early childhood wheezing: an 11-year prospective follow-up. Pediatr Pulmonol 2005, 40:316-326.

33. Jartti T, Korppi M, Ruuskanen O: The clinical importance of rhinovirusassociated early wheezing. Europ Respir J 2008, 32:314-315.

34. Kotaniemi-Syrjanen A, Vainionpaa R, Reijonen TM, Waris M, Korhonen $K$ Korppi M: Rhinovirus-induced wheezing in infancy: the first sign of children hood asthma? J Allergy Clin Immunol 2003, 111:66-71.

35. Lemanske RF, Jackson DJ, Gangnon RE, Evans MD, Li Z, Shult PA, Kirk CJ, Reisdorf E, Roberg KA, Anderson EL, Carlson-Dakes KT, Adler KJ, GilbertsonWhite S, Pappas TE, Dasilva DF, Tisler CJ, Gern JE: Rhinovirus illness during infancy predict subsequent childhood wheezing. J Allergy Clin Immunol 2005, 116:571-577.

36. Zar HJ, Ehrlich Rl, Workman L, Weinberg EG: The changing prevalence of asthma, allergic rhinitis and atopic eczema in African adolescents from 1995 to 2002. Pediatr Allergy Immunol 2007, 18:560-565.

37. Miller EK, Khuri-Bulos N, Williams JV, Shehabi AA, Faouri S, Al Jundi II Chen Q, Heil L, Mohamed Y, Morin L-L, Ali A, Halasa NB: Human rhinovirus C associated with wheezing in hospitalised children in the Middle East. $J$ Clin Virol 2009, 46:85-89.

38. Wisdom A, Kutkowska AE, McWilliam Leitch EC, Gaunt E, Templeton K, Harvala H, Simmonds P: Genetics, recombination and clinical features of human rhinovirus species C (HRV-C) infections; interactions of HRV-C with other respiratory viruses. PLoS One 2009, 4:e8518.

Pre-publication history

The pre-publication history for this paper can be accessed here: http://www.biomedcentral.com/1471-2334/11/65/prepub

doi:10.1186/1471-2334-11-65

Cite this article as: Smuts et al:: Human rhinovirus infection in young

African children with acute wheezing. BMC Infectious Diseases 2011 11:65.

\section{Submit your next manuscript to BioMed Central and take full advantage of:}

- Convenient online submission

- Thorough peer review

- No space constraints or color figure charges

- Immediate publication on acceptance

- Inclusion in PubMed, CAS, Scopus and Google Scholar

- Research which is freely available for redistribution 